\title{
Comparison of different land distribution mechanisms for a land-hungry region
}

\author{
Alim Gurtuev ${ }^{1, *}$, and Zaur Ivanov ${ }^{1}$ \\ ${ }^{1}$ Kabardino-Balkarian Scientific Center of the Russian Academy of Sciences, I.Armand st., 37a, \\ 360004, Nalchik, Russia
}

\begin{abstract}
This paper proposes an approach to the development an efficient land distribution mechanism for a particular land-hungry region. We separate budgetary and allocative efficiency and use general utility approach during evaluation of particular distribution mechanisms. We propose a model of potential land users, which allows quantifying the efficiency of a number of mechanisms of land distribution for land-hungry regions. Land users are represented as economic agents with bounded rationality and subjective utility functions. The model calculates allocation efficiency and budgetary efficiency as independent values and thus is more precise. It also has considerable flexibility and can be adjusted to specific agricultural technology and soil types. An analysis of the efficiency of various mechanisms for the test region showed that lottery mechanisms leads to losses of allocative efficiency compared with auction mechanisms. As for the budget revenues, the use of lottery mechanisms leads to much smaller losses of budgetary efficiency in comparison with simultaneous closed auctions of the first and second prices. But of all the mechanisms considered in the paper, the repetitive Vickrey auction leads to the smallest losses of budget efficiency in the model.
\end{abstract}

\section{Introduction}

The development of a regional system of agricultural production for post-collectivist mountainous land-hungry regions directly depends on the land reform solution $[1,2]$. For example, in many North Caucasian subjects of Russia, land reform in the part of the institutionalization of land ownership has not been carried out yet. In such regions, currently agricultural land is de jure owned by municipalities, but during the land reform it is expected that they will be transferred to agricultural producers [2-4]. In this regard, an important task is to construct or select a mechanism for the distribution of agricultural land between owners, since the wrong choice of such a mechanism will lead to a number of social losses, including:

- additional transaction costs of further redistribution;

- incomplete receipt of revenues to the state budget;

- reduction of the aggregate profit of agricultural producers;

- low rates of introduction of new technologies;

* Corresponding author: gurtuev@gmail.com 
- low competition;

- increased risk of land withdrawal from agricultural turnover;

- increased risk of reducing soil fertility;

- additional social tension.

An important theoretical aspect of the choice of the mechanism of distribution of farmland is the inherent conflict that is in the process of distribution itself - the participants' views on the fair distribution are different and come into conflict with each other. Therefore, the forecasting of distribution participants' strategies should be based on the provisions of the economic theory of conflicts [5, 6], and the choice of distribution mechanisms should take into account the problems of identifying preferences related to this circumstance.

Historically, various auctions have been used as mechanisms for the distribution of private goods in conflict situations [7-9]. This is indicated, in particular, by the names of some simple auctions in the literature: "English" (open auction with rising prices, nominated by participants), "Dutch" (open auction with downward prices), "Japanese" (open auction with ascending prices, appointed by the organizer). At the same time, the theory of auctions as effective distribution mechanisms was developed only in the second half of the XX century $[10,11]$. It should also be noted that the use of auction mechanisms implies a limited rationality of the auction participants [12]. Later, the use of auction theory allowed the creation of new effective auction mechanisms [13-16] (for example, Ausubel auction [17], the format of which was successfully used in the USA for the distribution of broadcasting frequencies). In modern auction theory, the basic principles for the creation of specific auctions have been developed depending on the goals of the auction organizer [18, 19 ], institutional methods of counteraction to collusion and corruption during auctions are being improved $[20,21]$.

\section{Materials and methods}

As an example object for our study we selected municipal agricultural land of the Stariy Cherek village (table 1). The village of Stariy Cherek is a typical municipal entity for the mountainous land-hungry region, it is located in the zone of intensive farming of the foothill plain zone of the Kabardino-Balkariya. The "Soviet Army named" kolkhoz (collective farm) was disbanded after the transfer of agricultural land to the municipality in 2005. Currently the main agricultural producers are tenants of farmland. More than half of them specialize in one production, and 22 tenants are relatively large (from 10 to 500 hectares).

The soil of the Stariy Cherek municipal formation is represented by typical preCaucasus chernozems (leached heavy loamy), with a comparatively high fertility level ( 55.6 bonitet, while the country's average score was 42.3 ). The soil texture is uniform, clayey, with an acid-base balance within the limits of the norm $(\mathrm{pH} \approx 5.4)$. The humus content in the arable layer is $3.28-4.8 \%$, the thickness of the humus layer is $60-90 \mathrm{~cm}-$ see original maps from municipality in fig. 1, 2 .

In assessing the effectiveness of various mechanisms for the allocation of land, we believe that all municipal farmlands are distributed. In practice, some of the land should be left in the municipal reserve (for the growth of the settlement, the development of infrastructure, etc.). On the issue of the mechanism for determining the size and location of these lands, there is currently a scientific and practical discussion requiring a separate discussion. 
Table 1. The main indicators of the land use system for Stariy Cherek village.

\begin{tabular}{|c|c|}
\hline Population (as of 01.01.2008) & 6681 \\
\hline Number of households & 1200 \\
\hline Total number of tenants & 306 \\
\hline Specialization of tenants & 150 \\
\hline Grain & 219 \\
\hline Vegetables & 211 \\
\hline Number of tenants with two or more production lines & 51 \\
\hline Lerennial and annual grasses & 50 \\
\hline Perennial plantations & 7 \\
\hline Area of farmland & 3958 \\
\hline Total area of farmland, ha & 3033 \\
\hline Total area of arable land, ha & 700 \\
\hline Total area of pastures, ha & 225 \\
\hline Total area of perennial plantations, ha & $835-1670$ \\
\hline Rent & 127 rubles \\
\hline Rent (for 1 hectare of pasture), rubles & 300 rubles \\
\hline Rent (for 1 hectare, many years old plants), rubles
\end{tabular}

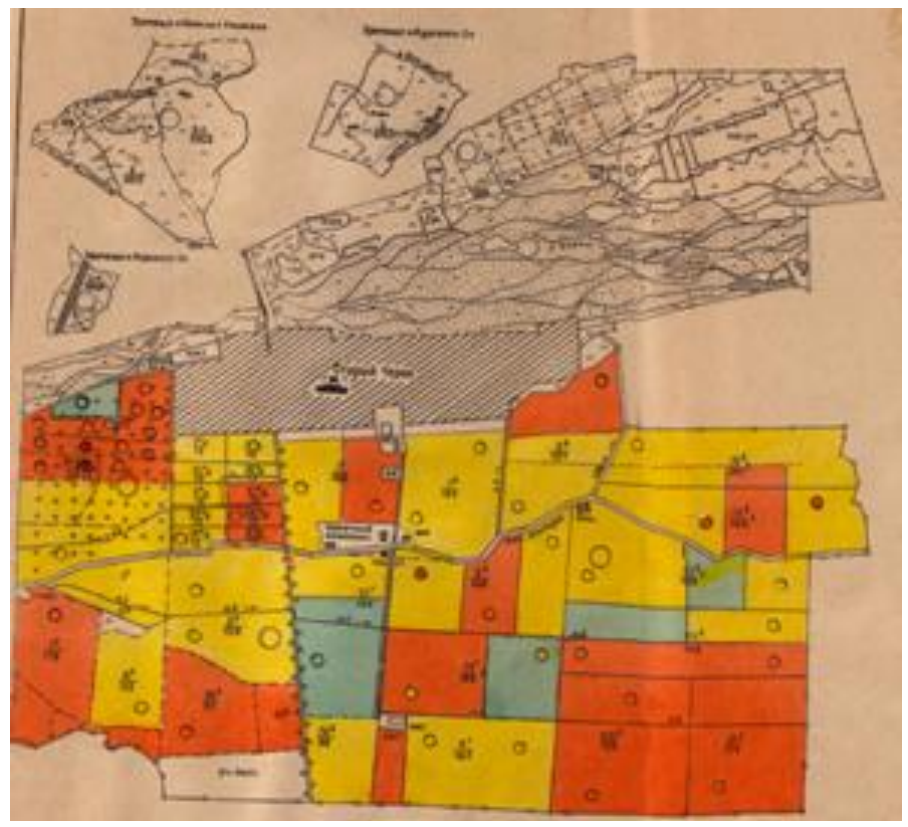

Fig. 1. Map of farmland in the Stariy Cherek municipality (K2O content). 


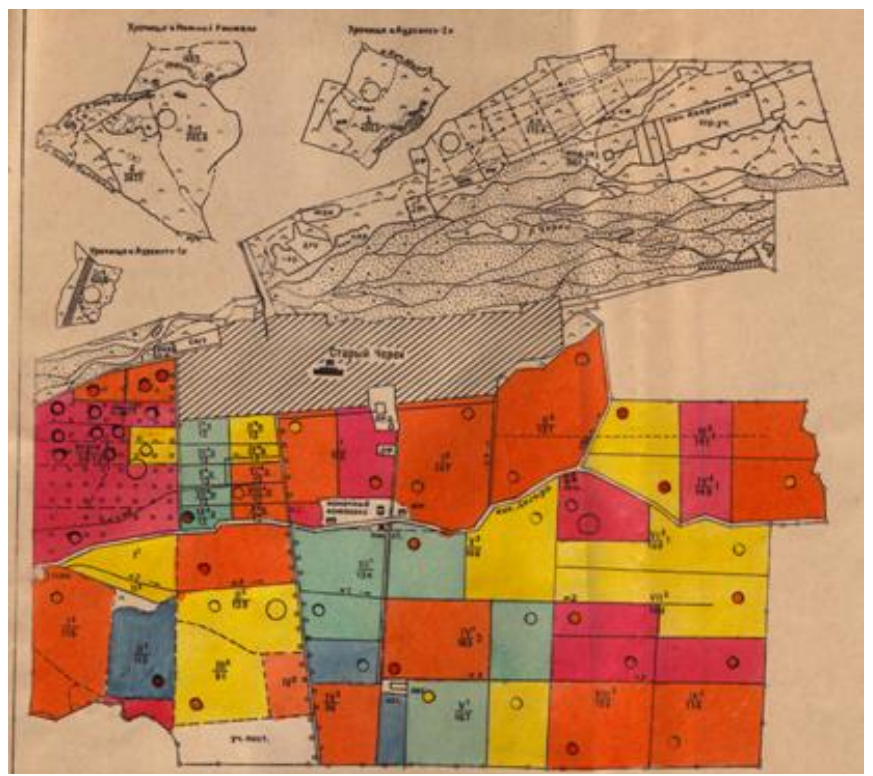

Fig. 2. Map of farmland in the Stariy Cherek municipality (P2O5 content).

\section{Model}

Let's consider as target indicators of efficiency of distribution of the farmland the following:

- Budget efficiency - budget revenues from distribution in form of the income from privatization or expectations of rental income, measured in rubles;

- Allocation efficiency - expected profit of agricultural producers, measured in rubles.

These indicators fully describe the benefits and costs of implementing each of the mechanisms considered for the regional economy.

Let each land user $j$ be characterized by two indicators:

$S_{j}$ - specialization (livestock, grain and technical, vegetables, fruits and berries), average annual profitability of the conditional plot (area of 1 hectare, a score of bonitet 50) with the corresponding type of activity, rub;

$M_{j}$ - available budget, rub.

Let each stead $i$ be characterized by the following set of indicators:

$A_{i}$ is the area, ha;

$T_{i}$ - type of stead (pasture, arable land, perennial plantations, haymaking), each type of stead is characterized by correction factors (from 0 to 1 ) to each type of land user specialization;

$B_{i}$ - fertility, bonitet points;

$D T_{i}$ - distance to the highway, km;

$D I_{i}$ - distance to the source of irrigation, $\mathrm{km}$;

$I C_{i}$ - possibility of irrigation, $I C_{i}=1$, if the plot is irrigated, 0 - if the plot is not irrigated.

We introduce the following basic restrictions:

1. The number of steads is greater than or equal to the number of applicants;

2. The steads inside are uniform in soil composition;

3. Transport network is available for all steads. 
As a utility function of land users, we will consider the expected average annual profitability.

$$
U=f\left(S_{j}, T_{i}, B_{i}, I C_{i}\right)
$$

Then the utility of site $i$ for land user $j$ is defined as formula 2 .

$$
U i j=f[\max \{\varphi(S j, T i)\}, A i, \beta(B i, I C i)]
$$

Where $\varphi\left(S_{j}, T_{i}\right)$ - an indicator characterizing the suitability of the type of site for a particular production direction, $\beta\left(B_{i}, I C_{i}\right)$ is an indicator characterizing the real soil fertility, taking into account the expected increase in production from the use of irrigation for a particular production direction.

For the purposes of the paper, let's assume that the utility of site $i$ for land user $j$ is calculated as formula (3).

$$
U i j=\max \{\varphi(S j, T i)\} \times A i \times \beta(B i, I C i)
$$

It is determined by the following algorithm: first the base utility of the site is determined, taking into account the specialization of the land user $\max \left\{\varphi\left(S_{j}, T_{i}\right)\right\}$.

$$
\beta(B i, I C i)=B i+B i I C i k
$$

where $\mathrm{k}=[0,1]$ depends on the activity, and then the final expected utility $U_{i j}$.

We assume that $U_{i j}$ is the maximum price that land user $j$ is willing to pay for the site $i$

Then the conditions for achieving maximum budget efficiency and maximum allocative efficiency with full information are the same.

The maximum allocative efficiency is achieved when Pareto-optimal allocation of land stead between land users in accordance with their utility $U_{i j}$.

$$
E Y \max =\max \Sigma U i j
$$

The maximum budget revenue from land privatization, provided that all stead are distributed among all land users so that each land user has acquired at least one site, is reached with the Pareto-optimal allocation of sites in accordance with their utility $U_{i j}$.

$$
\text { ERmax }=k s \times \max \Sigma U i j, k s>=1
$$

where $k s$ is a coefficient that depends on the planning horizon, showing how many times the expected annual profit is ready to be paid by the land user for the stead.

The maximum budget revenues for the allocation of land for lease are achieved with differentiated rental rates in the amount of

$$
\text { ERmax }=k l \times \max \Sigma U i j, 0<k l<1
$$

where $k l$ is the maximum share of the expected profit, on the basis of which it is possible to assign a rental rate.

\section{Results}

Consider the behavior of land users in the implementation of the following types of mechanisms for the allocation of land:

1. Lottery;

2. Closed auction of the first price (tender); 
3. Closed auction of the second price (Vickrey auction)

\subsection{Lottery}

During the discussion of the mechanisms for implementing land reform in land-hungry regions, there are many proposals to implement a lottery distribution mechanism that ensures the independence of the results. Such a mechanism is used, for example, at the present time in the distribution of land for lease in the village of Stariy Cherek. There are two options for implementing such a mechanism: with the conversion of the farmland in conventional ha according to soil quality and without such conversion.

The essence of this mechanism is simple: among all households of the municipality, a lottery with a dropout is held. Thus, random distribution of land plots between land users is achieved.

Let's estimate the effectiveness of the lottery mechanism of land distribution in our model (for $\mathrm{ks}=2, \mathrm{kl}=0.05$ ).

1. With conversion to the conventional ha according to bonitet (average size of the stead is 2.8 hectares, distribution by types of farmland: pastures -25 stead, arable land -1084 stead, perennial plantations -91 stead).

We calculate the mathematical expectations of $U_{i j}$ for each site and each land user with a random distribution according to the formula 8 .

$$
\mathrm{Uij}=[(25 / 1200) \times \mathrm{S} 1+(1084 / 1200) \times \mathrm{S} 2+(91 / 1200) \times \mathrm{S} 3] \times 2.8 \times 1
$$

Then the cumulative estimate of the distribution is

$U_{a}=\Sigma U_{i j}=57890$ thousand rubles.

Average annual losses from allocative inefficiency:

$L_{a}=E Y \max -E Y=61440-57890=3550$ thousand rubles.

Loss of budget efficiency:

at privatization

$L b=E R \max -E R=2 \times(61440-57890)=7,100$ thousand rubles.

average annual long-term lease

$L b=E R \max -E R=0.05 \times(61440-57890)=177.5$ thousand rubles.

2. Without conversion to the conventional ha (average size of the stead is 3.32 hectares, distribution by types of farmland: pastures -211 stead, arable land -912 stead, perennial plantations -77 stead)

We calculate the mathematical expectations of $U_{i j}$ for each site and each land user with a random distribution according to the formula 9.

$$
\mathrm{Uij}=[(211 / 1200) \times \mathrm{S} 1+(912 / 1200) \times \mathrm{S} 2+(77 / 1200) \times \mathrm{S} 3] \times 3.32 \times 1
$$

Then the cumulative estimate of the distribution is

$U a=\Sigma U i j=57771$ thousand rubles.

Average annual losses from allocative inefficiency:

$L a=E Y \max -E Y=65449-57771=7678$ thousand rubles.

Loss of budget efficiency:

at privatization

$L b=E R \max -E R=2 \times(65449-57771)=15356$ thousand rubles.

average annual long-term lease

$L b=E R \max -E R=0.05 \times(65449-57771)=383.9$ thousand rubles . 


\subsection{Tender}

Closed first-price auction is the main mechanism for the implementation of public procurement and the placement of government contracts in Russia at the present time. In our case, a tender can consist of several consecutive tours, to resolve situations in which in the first round several winners for one site are identified.

Let's estimate the effectiveness of this mechanism of land distribution in our model (for $k s=2, k l=0.05$, all parcels are distributed during the first round of the auction).

The expected gain of the land user $j$ from the acquisition of site $i$ in this case is expressed as follows.

$$
\pi i j=\pi i j(b i j ; U i j)=(U i j-b i j) P(b i j>b i x)
$$

where $b_{i j}$ is the reserve price of land user $j, b_{i x}$ - maximum between all other reserve prices.

Optimal price, as it stated in literature [22], there is $b_{i j}=U_{i j} / 2$

Since the distribution is in accordance with the values of $b_{i j}$, which proportionally depend on $U \mathrm{ij}$, the allocative Pareto-efficiency is achieved.

$$
E Y=E Y \max
$$

The estimation of the aggregate value of payments is

$U_{a}=\Sigma b_{i j}=32725.5$ thousand rubles.

Expected losses of budgetary efficiency:

at privatization

$L b=E R \max -E R=2 \times(65449-32725.5)=65449$ thousand rubles.

average annual long-term lease

$L b=E R \max -E R=0.05 \times(65449-32725.5)=1636.2$ thousand rubles.

\subsection{Vickrey auction}

Closed auctions of the second price, when the winner pays the second-highest bid, are not widely used in practice, despite the fact that they are theoretically very effective, since the participant's optimal bet is equal to the expected utility of the auction object for him. Such mechanisms are currently used in Internet auctions and Treasury bond auctions (in the USA). As well as the tender, the Vickrey auction in our case can consist of several consecutive tours, to resolve situations when several winners for one site are identified in the first round.

Let's estimate the effectiveness of this mechanism of land distribution in our model (for $k s=2, k l=0.05$, all parcels are distributed during the first round of the auction).

The optimal land user rate $j$ in acquiring site $i$ in this case coincides with the expected utility and is equal to $b i j=U i j$.

Since the distribution passes in accordance with the values of $U i j$, the allocative Pareto efficiency is achieved.

$$
E Y=E Y \max
$$

Then the cumulative estimate of the distribution is

$U a=\Sigma U i j=65449$ thousand rubles.

There is no loss of allocation efficiency.

The loss of budget efficiency at the Vickrey auction is due to the fact that the payment of the winner is less than its expected utility $U_{i j}$. For budget efficiency, the format of the auction - simultaneous or sequential - is of great importance. 
Expected losses of budgetary efficiency for our case with simultaneous Vickrey auction: at privatization

$L b=E R \max -E R=2 \times 20695.6=41391.1$ thousand rubles.

average annual long-term lease

$L b=E R \max -E R=0.05 \times 20695.6=1034.8$ thousand rubles.

The expected loss of budgetary efficiency with the repetitive Vickrey auction with a step of 1000 rubles:

at privatization

$L b=E R \max -E R=2 \times 132.8+909=1174.6$ thousand rubles.

average annual long-term lease

$L b=E R \max -E R=0.05 \times 132.8+909=97.5$ thousand rubles.

\section{Conclusions}

The proposed model of the behavior of potential land users, allows you to quantify the effectiveness of various mechanisms of land distribution. At the same time, the more accurate and complete the initial data, the more accurate the final score is obtained. Land users are represented in the form of economic agents with limited rationality and subjective utility, which makes it possible to use the model for any regions and land use systems. Separation of assessments of allocative and budgetary effectiveness allows more precise determination of the scope of application of a particular land allocation mechanism. The model is easy to use and has considerable flexibility - the assessment of specialization of land users is adjusted for specific agricultural technologies and soil types.

Analysis of the effectiveness of using closed auctions for the distribution of farmland showed that, with both a simple tender for the first price and Vickrey's auction, the optimal allocation of plots is achieved in the model. The use of lottery mechanisms, on the contrary, leads to losses of allocative efficiency (up to $11.7 \%$ ).

With regard to direct budget revenues, the use of lottery mechanisms leads to much smaller losses of budgetary efficiency in comparison with simultaneous closed auctions of the first and second prices. At the same time, the successive Vickrey auction outperforms the lottery mechanisms in both allocative and budgetary efficiency.

The conversion of farmland to conventional ha when implementing the lottery distribution mechanism leads to an increase in both budgetary and allocative efficiency of land distribution. At the same time, the gain in budget efficiency is more than $100 \%$.

At the same time, due to potential losses associated with the discrepancy of the conversion factor in terms of ha expected profitability of different production areas, the real gain from the transfer of farmland in cond. ha may be less, for example, for St. Cherek it is $0.2 \%$ of the base estimate of farmland.

Of all the mechanisms considered, the use of the successive Vickrey auction leads to the smallest losses of budget efficiency in the model. When it is used, full allocative efficiency is achieved, and the estimate of budgetary efficiency losses during privatization is 1,174.6 rubles, which is 6 times less than in case of a lottery mechanism with conversion.

The research was supported by the Russian Foundation of Basic Research, grant No. 19-010-00376 A "Mechanisms for screening innovation projects on the basis of the analysis of tacit knowledge" and grant No. 20-010-00269A "A mechanism for mountainous regions development management on the basis of a the new architecture of local socio-economic systems".

\section{References}

1. A.W. Horowitz, AER 83(4), 1003-1010 (1993). https://www.jstor.org/stable/i337070 
2. Z. Lerman, N. Shagaida, American Agricultural Economics Association Annual Meeting (Providence, RI, 2005). DOI: 10.22004/ag.econ.19461

3. D. Rylko, R. Jolly, Comparat. Econ. Stud. 47(1), (2005). DOI: 10.1057 /palgrave.ces.8100087

4. V. Uzun, Comparat. Econ. Stud. 47(1), (2005). DOI: 10.1057/palgrave.ces. 8100078

5. T. Schelling, The Strategy of Conflict (Harvard UP, 1980). DOI: $10.1177 / 002200275800200301$

6. A. Ispano, P. Schwardmann, Games and Econ. Behavior 105, 329-348 (2017). DOI: 10.1016/j.geb.2017.08.008

7. K. Hendricks, R.H. Porter, Handbook of Industrial Organization 3, 2073-2144 (2007). DOI: $10.1016 / \mathrm{S} 1573-448 \mathrm{X}(06) 03032-9$

8. E. Cantillon, M. Pesendorfer, CEPR Discussion Paper 6083, (2007). DOI: https://cepr.org/active/publications/discussion_papers/dp.php?dpno=6083

9. K. Back J. F. Zender, Econ. Letters 73(1), 29-34 (2001). DOI: 10.1016/S01651765(01)00465-7

10. L. Ausubel, P. Cramton, M. Pycia, M. Rostek, M. Weretka Rev. Econ. Stud. 81(4), 1366-1400 (2014). DOI: 10.1093/restud/rdu023

11. A. Hortaçsu, D. McAdams, JEL 56(1), 157-184 (2018). DOI: 10.1257/jel.20160961

12. A.O. Gurtuev, Z.Z. Ivanov, E.G. Derkach, Izvestiya KBNC RAN 6, 45-50 (2017)

13. R. Deb, M.M. Pai, AEJ: Microeconomics 9(1), 275-314 (2017). DOI: $10.1257 / \mathrm{mic} .20150121$

14. S. Tadelis, F. Zettelmeyer, AER 105(2), 886-905 (2015). DOI: 10.1257/aer.20110753

15. S. Loertscher, L.M. Marx, T. Wilkening, JEL 53(4), 857-897 (2015). DOI: $10.1257 /$ jel.53.4.857

16. X. Che, T. Klumpp, AEJ: Microeconomics 8(2), 168-201 (2016). DOI: $10.1257 / \mathrm{mic} .20140137$

17. L. Ausubel, AER 94(5), 1452-1475 (2004). DOI: 10.1257/0002828043052330

18. P. Klemperer, JEP 16(1), 169-189 (2002). DOI: 10.1257/0895330027166

19. E. Maskin, European Econ. Rev. 44, 667-681 (2000). DOI: 10.1016/S00142921(00)00057-X

20. P. Crampton, J. Schwartz, J. Regulatory Econ. 17 (2000). DOI: $10.1023 / \mathrm{A}: 1008174031940$

21. R. Burguet, AEJ: Microeconomics 9(2), 315-341 (2017). DOI: 10.1257/mic.20150105

22. P. Klemperer, JES 13(3), 227-286 (1999). DOI: 10.1111/1467-6419.00083 